\title{
Chronic Inhibition of Nitric Oxide in Central Nervous System Does Not Cause Hypertension
}

\author{
Yoshifumi Wada, Hidehiro Matsuoka, Seiya Okuda, and Tsutomu Imaizumi
}

\begin{abstract}
Acute inhibition of nitric oxide (NO) synthase in the brain causes elevation of blood pressure and sympathetic excitation under anesthetized conditions. To investigate chronic effects of NO synthase inhibition in the central nervous system on blood pressure regulation in conscious unrestrained animals, we administered $N^{\mathrm{G}}$-monomethyl-L-arginine (L-NMMA), a potent NO synthase inhibitor, at low (22.5 $\mu \mathrm{mol} / \mathrm{kg})$ and high $(67.5 \mu \mathrm{mol} / \mathrm{kg})$ doses for $1 \mathrm{wk}$ into the cisterna magna with an osmotic pump and measured mean arterial pressure (MAP) and heart rate (HR) by a telemetry method. The same dose of $N^{\mathrm{G}}$-monomethyl-D-arginine (D-NMMA), an inactive isomer of L-NMMA, was administered to control rats. Chronic intracisternal administration of low-dose L-NMMA significantly decreased the brain nitrite/nitrate and NO metabolite contents as compared with D-NMMA $(p<0.05)$. However, MAP and its variability, HR and its variability, and plasma norepinephrine levels did not differ between the two groups of rats at either low- or high-dose treatment. Thus, chronic NO synthase inhibition in the central nervous system did not affect systemic hemodynamics or plasma norepinephrine concentrations despite the inhibition of brain NO. Our results suggest that endogenous NO in the central nervous system, at least as a whole, may not affect the systemic hemodynamics of chronic unanesthetized rats. (Hypertens Res 1998; 21: 97-101)
\end{abstract}

Key Words: brain, sympathetic nervous system, blood pressure variability, nitrate

The central nervous system and neuro-humoral activation play a pivotal role in the pathogenesis of hypertension $(1,2)$. Nitric oxide (NO) synthase is localized in the nucleus tractus solitarius (NTS) and rostroventrolateral medulla (RVLM) $(3,4)$, suggesting that endogenous NO participates in neural regulation of blood pressure, independent of its direct actions on blood vessels (5). We previously demonstrated that approximately $40 \%$ of NTS neurons respond to NO synthase inhibition in rat brain slices (6). Furthermore, we found that microinjection of an NO synthase inhibitor into NTS elicited blood pressure elevation and sympathoexcitation in rabbits (7). Similar findings were reported with intracisternal injection of NO synthase inhibitors in rats $(8)$ or with injection of NO into the RVLM in cats $(9,10)$ and rats (11), indicating that endogenous $\mathrm{NO}$ may affect the sympathetic outflow tonically via a direct action in the brain stem. However, since these acute experiments were conducted under the anesthetized conditions with deafferentation, it remains unknown whether neuronal NO in the central nervous system has a role in long-term blood pressure regulation. To examine the effect of chronic NO synthase inhibition in the brain on hemodynamics, we measured blood pressure and heart rate in con- scious unrestrained rats by a telemetry system during the continuous administration of $N^{\mathrm{G}}$-monomethyl-L-arginine, an NO synthase inhibitor, into the cisterna magna for $7 \mathrm{~d}$.

\section{Methods}

Animals

Male Wistar rats weighing 240-260 g, obtained from Japan SLC Inc. (Shizuoka, Japan), were fed normal rat chow (CE-2, Clea Japan, Tokyo), which contained of $110 \mathrm{mmol}$ of sodium and $280 \mathrm{mmol}$ of potassium. Throughout the study period, animals were housed in a room at constant temperature (25 $\left.\pm 1^{\circ} \mathrm{C}\right)$ and humidity $(60 \pm 5 \%)$. The room was lighted automatically from 7 AM to 7 PM. Rats were provided free access to water and rat chow. Animal care and treatment were conducted in accordance with institutional guidelines that complied with international laws and policies (EEC Council Directive 86/609, OJL 358, Dec. 1987; NIH Guide for the Care and Use of Laboratory Animals, NIH Publication No. 85-23, 1985).

Intracisternal Catheter Implantation

After the rats were anesthetized with pentobarbital

From the Department of Internal Medicine III, Kurume University School of Medicine, Kurume, Japan.

This study was supported in part by Grants-in-Aid for Scientific Research from the Ministry of Education, Science, and Culture, Tokyo, and Kimura Memorial Heart Foundation, Kurume.

Address for Reprints: Hidehiro Matsuoka, M.D., Ph.D., Department of Internal Medicine III, Kurume University School of Medicine, 67 Asahi-machi, Kurume, Fukuoka 830-0011, Japan.

Received December 8, 1997; accepted in revised form April 3, 1998. 
sodium $(50 \mathrm{mg} / \mathrm{kg}$, ip), a saline-filled Silastic PE10 tube (Imamura Rubber Co., Tokyo) connected to a PE50 tube was implanted stereotaxically into the cisterna magna and exteriorized at the neck. The end of the PE50 tube was plugged with a pin. Each animal received postoperative chrolomycin $(40 \mathrm{mg} /$ $\mathrm{kg}$, Sankyo, Japan) topically and intraperitoneally for $3 \mathrm{~d}$ after surgery.

\section{Telemetry and Data Acquisition}

We used a Dataquest IV system (Data Sciences Inc., MN) to measure mean arterial pressure (MAP) and heart rate (HR) by telemetry $(12,13)$. The monitoring system consisted of a transmitter (radio-frequency transducer; TA11PA-C40, Data Science), receiver panel, consolidation matrix, and IBM personal computer (IBM PC-750) with accompanying software. Immediately after implantation of the intracisternal catheter, a flexible catheter transmitter was surgically secured to the abdominal aorta just below the renal arteries. The transmitter was sutured onto the abdominal wall. Rats were housed in individual cages after surgery.

Each cage was placed over a receiver panel connected to a personal computer for data storage onto the hard drive. With the Dataquest system, the rats were completely unrestrained and were free to move in their individual cages. After regaining their preoperative weight ( $5 \mathrm{~d}$ after surgery), hemodynamic data were sampled every $5 \mathrm{~min}$ for $10 \mathrm{~s}$ throughout the experiment. Catheter patency was verified by observing the wave forms stored at the time of hemodynamic data sampling. On average, hemodynamic data for a total of $9 \mathrm{~d}$ were collected for each animal. This period included $2 \mathrm{~d}$ before implantation of the osmotic pump as a control period and $7 \mathrm{~d}$ during infusion of chemicals. Blood pressure, heart rate, and their variabilities during daytime (07:00-19:00 h) and nighttime (19:00-07:00 h) were also analyzed separately.

\section{Osmotic Minipump Implantation}

Five days after catheter implantation and a 2-d control period, rats were anesthetized with pentobarbital sodium $(50 \mathrm{mg} / \mathrm{kg}$, ip) and were randomly assigned to receive $N^{\mathrm{G}}$-monomethyl-L-arginine (L-NMMA) or $N^{\mathrm{G}}$-monomethyl-D-arginine (DNMMA), an optical isomer of L-NMMA that has no effect on NO synthase activity. The intracisternal catheter placed under the skin of the neck was connected to an osmotic minipump (Alzet 2001, Alzet Co., CA), which was used to infuse L-NMMA or DNMMA at $2.2 \mathrm{nmol} / \mathrm{kg} / \mathrm{min}(22.5 \mu \mathrm{mol} / \mathrm{kg}$ in total; $n=8$, for each) or at $6.6 \mathrm{nmol} / \mathrm{kg} / \mathrm{min}(67.5$ $\mu \mathrm{mol} / \mathrm{kg}$ in total; $n=6$, for each) for $7 \mathrm{~d}$.

\section{Chemical Analysis}

At the end of experiment, blood samples were obtained, immediately placed in ice, and centrifuged at $1,800 \times g$ at $4^{\circ} \mathrm{C}$. The plasma was stored at $-80^{\circ} \mathrm{C}$ until analysis. The plasma concentrations of norepinephrine (PNE) were determined by highperformance liquid chromatography with electrochemical detection (HLC-725CA, Tohso, Japan).
After blood sampling, the whole brain was saved at $-80^{\circ} \mathrm{C}$ for chemical analysis. The frozen brain was rapidly minced and placed in ice-cold $0.3 \mathrm{~N}$ perchloric acid (total volume, $12 \mathrm{ml}$ ). Immediately after the brain was homogenized, the homogenate was centrifuged at $20,000 \times g$ for $20 \mathrm{~min}$, and the supernatant was stored at $-80^{\circ} \mathrm{C}$ until analysis. Brain nitrite/nitrate $\left(\mathrm{NO}_{\mathrm{x}}\right)$ and $\mathrm{NO}$ metabolite contents were measured by a colorimetric assay based on the Griess reaction (14).

\section{Statistical Analyses}

All data are expressed as means \pm standard error of the mean unless otherwise indicated. Hemodynamic data were compared by analysis of variance (ANO VA) and, when appropriate, with Scheffe's test for multiple comparisons. Brain $\mathrm{NO}_{\mathrm{x}}$ levels and plasma norepinephrine concentrations were compared by unpaired- $t$ test.

\section{Results}

\section{Body Weight}

There were no significant differences in body weight between rats treated with L-NMMA and those treated with D-NMMA $(22.5 \mu \mathrm{mol} / \mathrm{kg}$ for each) at the beginning (L-NMMA, $260 \pm 7$; D-NMMA, $249 \pm 6$ $\mathrm{g}, \mathrm{NS}$ ) or at the end of experiments (L-NMMA, 288 \pm 8 ; D-NMMA, $298 \pm 4 \mathrm{~g}$, NS), indicating that chronic NO synthase inhibition did not affect the growth of rats.

\section{Hemodynamics}

Figure 1 shows the 24-h mean arterial pressure (MAP) before and during chronic intracisternal infusion of L-NMMA or D-NMMA. Neither L-NMMA nor D-NMMA at the low dose affected the 24-h MAP (NS, ANOVA, Fig. 1). Similarly, 24-h heart rate (HR) was not affected by either L-NMMA or D-NMMA at the low dose (Fig. 1). To examine the effect of chronic brain NO synthase inhibition on hemodynamic variability, we analyzed the daytime and nighttime standard deviations of MAP and of HR before and during L-NMMA or D-NMMA at the low dose (Table 1). Variabilities of MAP and of HR remained constant and were similar in both groups.

To exclude the possibility that the dose used in this experiment was insufficient to inhibit NO synthase, we conducted further experiments using three-fold higher doses of L-NMMA and D-NMMA $(67.5 \mu \mathrm{mol} / \mathrm{kg} / \mathrm{wk}$ for each). Even with high-dose treatment, MAP (pre L-NMMA, $91.3 \pm 3.2$; during L-NMMA, $90.9 \pm 1.8$; pre D-NMMA, $84.1 \pm 0.8$; during D-NMMA, $84.9 \pm 0.5 \mathrm{mmHg}$, NS) and HR (pre L-NMMA, $301 \pm 5$; during L-NMMA, $297 \pm 2$ : pre D-NMMA, $320 \pm 3$; during D-NMMA, $323 \pm 2$ bpm, NS) were not altered and did not differ between the group given L-NMMA and that given DNMMA.

\section{Plasma Norepinephrine Concentration}

There was no significant difference in the plasma norepinephrine concentration between L-NMMA 
Table 1. Effects of Chronic Intracisternal Infusion of D-NMMA or L-NMMA on Systemic Hemodynamics

\begin{tabular}{|c|c|c|c|c|}
\hline & \multicolumn{2}{|c|}{ D-NMMA $(n=8)$} & \multicolumn{2}{|c|}{ L-NMMA $(n=8)$} \\
\hline & Control & Drug & Control & Drug \\
\hline \multicolumn{5}{|c|}{ MAP $(\mathrm{mmHg})$} \\
\hline All day & $90.3 \pm 1.6$ & $89.0 \pm 0.6$ & $93.3 \pm 1.8$ & $94.0 \pm 0.9$ \\
\hline Daytime & $90.6 \pm 1.7$ & $88.8 \pm 0.7$ & $93.9 \pm 1.9$ & $94.3 \pm 0.9$ \\
\hline Nighttime & $90.0 \pm 1.4$ & $89.0 \pm 0.6$ & $92.5 \pm 1.7$ & $93.9 \pm 0.9$ \\
\hline \multicolumn{5}{|c|}{ MAP variability $(\mathrm{mmHg})$} \\
\hline All day & $5.0 \pm 0.2$ & $5.4 \pm 0.2$ & $5.4 \pm 0.3$ & $6.0 \pm 0.2$ \\
\hline Daytime & $4.7 \pm 0.2$ & $5.1 \pm 0.3$ & $5.2 \pm 0.2$ & $5.8 \pm 0.2$ \\
\hline Nighttime & $5.1 \pm 0.3$ & $5.6 \pm 0.2$ & $5.4 \pm 0.3$ & $5.9 \pm 0.2$ \\
\hline \multicolumn{5}{|c|}{ Heart rate (beats/min) } \\
\hline All day & $328 \pm 3$ & $319 \pm 3$ & $327 \pm 3$ & $327 \pm 3$ \\
\hline Daytime & $321 \pm 4$ & $310 \pm 3$ & $319 \pm 4$ & $318 \pm 4$ \\
\hline Nighttime & $341 \pm 5$ & $335 \pm 4$ & $334 \pm 3$ & $339 \pm 4$ \\
\hline \multicolumn{5}{|c|}{ Heart rate variability (beats/min) } \\
\hline All day & $28.5 \pm 1.9$ & $27.0 \pm 0.9$ & $27.3 \pm 1.1$ & $30.0 \pm 1.1$ \\
\hline Daytime & $23.2 \pm 1.7$ & $19.5 \pm 0.9$ & $24.1 \pm 1.2$ & $24.0 \pm 0.9$ \\
\hline Nighttime & $32.0 \pm 2.9$ & $31.0 \pm 1.3$ & $27.3 \pm 1.4$ & $28.0 \pm 1.1$ \\
\hline
\end{tabular}

Values are expressed as means \pm SEM. D-NMMA, $N^{\mathrm{G}}$-monomethyl-D-arginine; L-NMMA, $N^{\mathrm{G}}$-monomethyl-L-arginine; MAP, mean arterial pressure. There were no significant differences between either group or period.
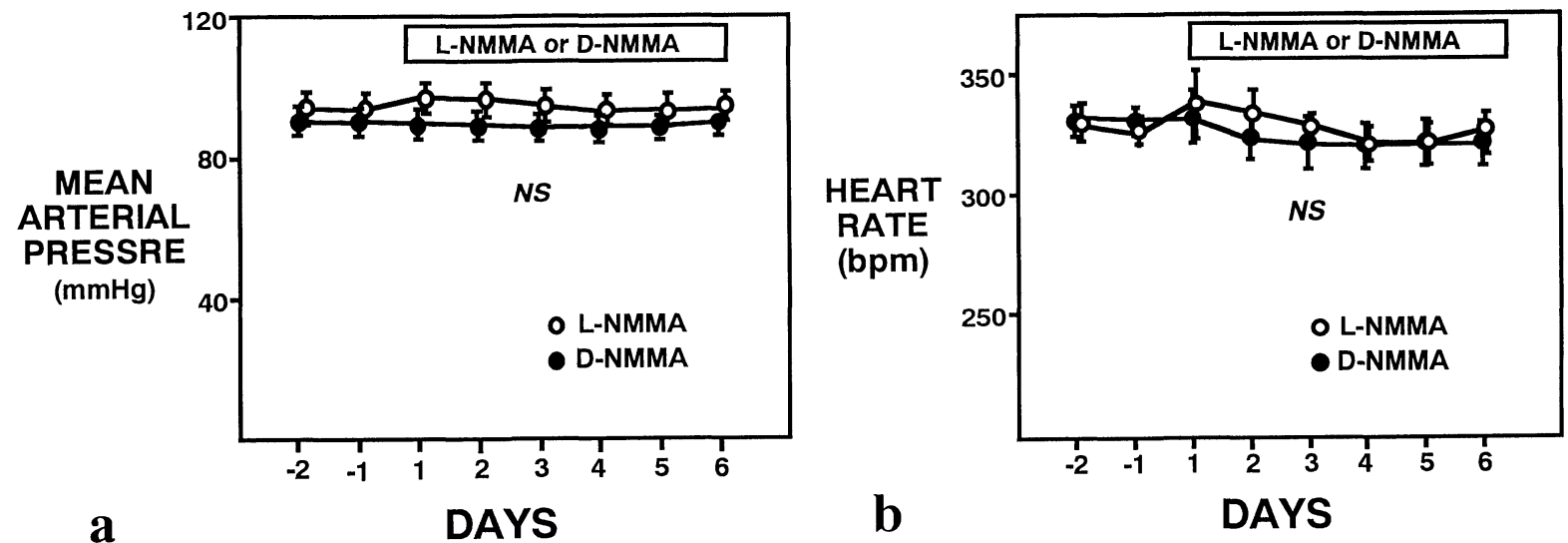

Fig. 1. Chronic effects of intracisternal administration of $\mathrm{N}^{\mathrm{G}}$-monomethyl-L-arginine (L-NMMA; $\left.22.5 \mu \mathrm{mol} / \mathrm{kg}\right)$, a nitric oxide synthase inhibitor, and $\mathrm{N}^{G}$-monomethyl-D-arginine (D-NMMA; $\left.22.5 \mu \mathrm{mol} / \mathrm{kg}\right)$, an inactive isomer of L-NMMA, on mean arterial pressure (a) and heart rate (b). Neither L-NMMA or D-NMMA affected mean arterial pressure or heart rate during 7 days of treatment. Values are the mean $\pm \operatorname{SEM}(\mathrm{n}=8)$.

$(22.5 \mu \mathrm{mol} / \mathrm{kg})$-treated $(963 \pm 183 \mathrm{pg} / \mathrm{ml})$ rats and $\mathrm{D}$ NMMA $(22.5 \mu \mathrm{mol} / \mathrm{kg})$-treated $(960 \pm 263 \mathrm{pg} / \mathrm{ml})$ rats (NS).

\section{Brain $\mathrm{NO}_{x}$ Contents}

Brain contents of $\mathrm{NO}_{\mathrm{x}}$ were significantly lower in the L-NMMA $(22.5 \mu \mathrm{mol} / \mathrm{kg})$-treated rats than in the D-NMMA (22.5 $\mu \mathrm{mol} / \mathrm{kg}$ )-treated rats (Fig. 2), suggesting that L-NMMA significantly inhibited brain NO synthase.

\section{Discussion}

In the present study, we demonstrated that chronic
NO synthase inhibition in the brain did not affect systemic hemodynamics or plasma norepinephrine concentrations in conscious unrestrained rats, despite significant inhibition of brain NO synthesis. Our results suggest that endogenous NO in the central nervous system, at least as a whole, may not play a role in long-term blood pressure regulation.

\section{Chronic Brain NO Synthase Inhibition}

Because intra-cisterinally administered L-NMMA may leak into the systemic circulation and increase blood pressure, we administered a very small dose of L-NMMA $(2.2 \mathrm{nmol} / \mathrm{kg} / \mathrm{min})$. The cumulative dose of L-NMMA was $1 \mu \mathrm{mol}$ over $24 \mathrm{~h}$. It is rather 


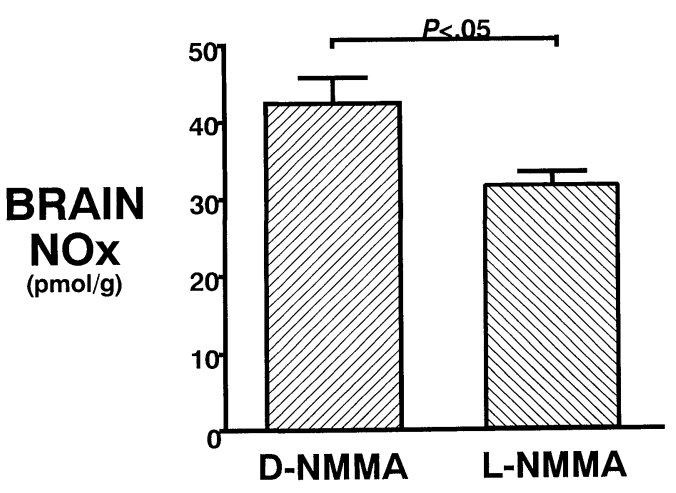

Fig. 2. Chronic effects of intracisternal administration of $\mathrm{N}^{G}$-monomethyl-L-arginine (L-NMMA; $\left.22.5 \mu \mathrm{mol} / \mathrm{kg}\right), \quad a$ nitric oxide synthase inhibitor, and $\mathrm{N}^{G}$-monomethyl-Darginine (D-NMMA; $22.5 \mu \mathrm{mol} / \mathrm{kg})$, an inactive isomer of $L-N M M A$, on contents of brain nitrite/nitrate $\left(N O_{x}\right), a$ stable metabolites of NO. Chronic L-NMMA treatment significantly attenuated brain $N O$ synthesis $(\mathrm{p}<0.05)$. Values are the means $\pm S E M(\mathrm{n}=8)$.

difficult to compare a dose of L-NMMA infused chronically over $7 \mathrm{~d}$ with doses injected over seconds or minutes, as reported by other investigators. Togashi et al. administered $1 \mu \mathrm{mol}$ of $\mathrm{L}-$ NMMA intra-cisternally over $1 \mathrm{~min}$ in rats, which raised blood pressure by approximately $6 \mathrm{mmHg}$ (8). Other investigators injected L-NMMA into the NTS at 64 nmol over a few minutes (7) in rabbits, into the RVLM at $0.3 \mu \mathrm{mol}$ over short periods in cats (10), and into the ventrolateral medulla at 15 $\mu \mathrm{mol}$ over short periods in cats (9). Thus, the dose used in this study was rather small. However, the failure of L-NMMA to raise blood pressure was probably not due to an inadequate dose, because brain NO synthesis was inhibited by the lower dose of L-NMMA (Fig. 2). Although we did not measure brain $\mathrm{NO}_{\mathrm{x}}$ at the three-fold higher dose of $\mathrm{L}$ NMMA, it is feasible to assume that brain NO synthesis was further inhibited. Since NO synthase, estimated on the basis of NO metabolite content, was not completely blocked by chronic L-NMMA treatment, the failure of intracisternally administered L-NMMA to raise blood pressure may be attributed to preserved NO synthesis in the brain. We have verified effective diffusion of L-NMMA over the whole brain by intracisternal infusion of dye administered in the same manner as L-NMMA (our preliminary experiments).

\section{Hemodynamic Effect of Chronic Brain NO Synthase Inhibition}

Previous studies demonstrated that acute administration of NO synthase inhibitors into the cerebral ventricle (8), NTS (7), and RVLM (9-11) causes sympathoexcitation and blood pressure elevation. Long-term experiments have shown that renal denervation (15) and systemic chemical sympathectomy (16) attenuates or delays hypertension induced by chronic NO synthesis inhibition. These results suggest that NO in the brain suppresses tonic sym- pathetic outflow via a central mechanism. In the present study, chronic NO synthase inhibition in the brain did not affect blood pressure, heart rate, or their variabilities. Moreover, the plasma norepinephrine concentration as an index of sympathetic nerve activity was not altered. The discrepancies between previous results and ours may have derived from two methodological differences, i.e., 1) the method for central NO inhibition and 2) the method for hemodynamic measurements. Previous studies showing that brain NO synthase inhibition caused sympathoexcitation and pressor effects were performed in an acute setting under anesthetized conditions (7-11), whereas we administered an NO synthase inhibitor intracisternally for $1 \mathrm{wk}$ and measured systemic hemodynamics continuously in conscious, unrestrained animals. Thus, the method of hemodynamic measurement, rather than that of NO synthase inhibition, may account for the differences between previous results and ours. It is also possible that counterregulatory mechanisms in the central nervous system acting against NO synthase inhibition may account for the insignificant changes in hemodynamic variables in our chronic experiments.

\section{Study Limitations}

In the present study, we examined the effect of intracisternal L-NMMA, an L-arginine analogue that non-specifically inhibits both endothelial and neuronal NO synthase (17). Although we cannot determine whether our findings resulted from the inhibition of endothelial NO synthase or from the inhibition of neuronal NO synthase, the finding that neuronal NO synthase knockout mice did not show any hemodynamic abnormalities may be in accordance with our results (18). We administered the NO synthase inhibitor intracisternally in this study. LNMMA injected into the RVLM increases blood pressure, whereas L-NMMA injected into the caudal ventrolateral medulla (CVLM) lowers blood pressure (9). It has also been shown that the expression of NO synthase mRNA is differentially regulated in the hypothalamus and the caudal ventral medulla (19). Thus, in this study we cannot exclude the possibility that generalized inhibition of NO synthase may have offset the diverse effects of NO in the brain. In previous reports, arterial baroreceptor deafferentation was conducted to eliminate the influence of afferent neural input from arterial baroreceptors $(7,8)$, whereas afferent nerves were kept intact in the present study. Thus, the baroreflex may have offset the pressor effect elicited by central NO synthase inhibition.

In summary, we demonstrated that chronic inhibition of brain NO synthesis had no effects on systemic hemodynamics or plasma norepinephrine levels. Our result suggest that brain NO as a whole may not play a role in long-term blood pressure control.

\section{Acknowledgements}

The authors are grateful to Mses. Tamami Iguchi and Shino Yamakawa for their excellent technical assistance. 


\section{References}

1. Dampney RAL: Functional organization of central pathways regulating the cardiovascular system. Physiol Rev 1994; 74: 323-364.

2. Oparil S, Chen Y-F, Berecek KH, Callhoun DA, Wyss JM: The role of the central nervous system in hypertension. in Laragh $\mathrm{JH}$, Brenner BM (eds): Hypertension; Pathophysiology, diagnosis, and management, 2nd ed. New York, Raven Press, 1995, pp 713-740.

3. Bredt DS, Hwang PM, Snyder SH: Localization of nitric oxide synthase indicating a neural role for nitric oxide. Nature 1990; 347: 768-770.

4. Ohta A, Takagi H, Matsui T, Hamai Y, Iida S, Esumi H: Localization of nitric oxide synthase-immunoreactive neurons in the solitary nucleus and ventrolateral medulla oblongata of the rat: their relation to catecholaminergic neurons. Neurosci Lett 1993; 158: 33-35.

5. Garthwaite J, Boulton CL: Nitric oxide signaling in the central nervous system. Annu Rev Physiol 1995; 57: 683-706.

6. Tagawa $\mathrm{T}$, Imaizumi $\mathrm{T}$, Harada $\mathrm{S}$, et al: Nitric oxide influences neuronal activity in the nucleus tractus solitarius of rat brainstem slices. Circ Res 1994; 75: 70-76.

7. Harada S, Tokunaga S, Momohara M, et al: Inhibition of nitric oxide formation in the nucleus tractus solitarius increases renal sympathetic nerve activity in rabbits. Circ Res 1993; 72: 511-516.

8. Togashi H, Sakuma I, Yoshioka M, et al: A central nervous system action of nitric oxide in blood pressure regulation. J Pharmacol Exp Ther 1992; 262: 343-347.

9. Shapoval LN, Sagach VF, Pobegailo LS: Nitric oxide influences ventrolateral medullary mechanisms of vasomotor control in the cat. Neurosci Lett 1991; 132: 47-50.

10. Zanzinger $\mathbf{J}$, Czachurski $\mathbf{J}$, Seller $\mathrm{H}$ : Inhibition of basal and reflex-mediated sympathetic activity in the RVLM by nitric oxide. Am J Physiol 1995; 268: R958-R962.

11. Tseng CJ, Liu HY, Lin HC, Ger LP, Tung CS, Yen $\mathrm{MH}$ : Cardiovascular effects of nitric oxide in the brain stem nuclei of rats. Hypertension 1996; 27: 3642.

12. Brockway BP, Mills PA, Azar SH: A new method for continuous chronic measurements and recordings of blood pressure, heart rate, and activity in the rat via radio-telemetry. Clin Exp Hypertens 1991; A13: 885-895.

13. Guiol C, Ledoussal C, Surgé JM: A radiotelemetry system for chronic measurement of blood pressure and heart rate in the unrestrained rat: validation of the method. J Pharmacol Toxicol Methods 1992; 2: 99-105.

14. Green LC, Wagner DA, Glogowski J, Skipper P, Wishnok J, Tannenbaum S: Analysis of nitrate, nitrite and $[15 \mathrm{~N}]$ nitrate in biological fluids. Anal Biochem 1982; 126: 131-138.

15. Matsuoka H, Nishida $H$, Nomura G, Van Vliet BN, Hironori $\mathrm{T}$ : Hypertension induced by nitric oxide synthesis inhibition is renal nerve dependent. Hypertension 1994; 23: 971-975.

16. Sander M, Hansen PG, Victor RG: Sympathetically mediated hypertension caused by chronic inhibition of nitric oxide. Hypertension 1995; 26: 691-695.

17. Fukuto JM, Chaudhuri G: Inhibition of constitutive and inducible nitric oxide synthase: potential selective inhibition. Annu Rev Pharmacol Toxicol 1995; 35: $165-194$.

18. Huang Z, Huang PL, Panahian N, Dalkara T, Fishman MC, Moskowitz MA: Effects of cerebral ischemia in mice deficient in neuronal nitric oxide synthase. Science 1994; 265: 1883-1885.

19. Krukoff TL, Gehlen F, Ganten D, Wagner J: Gene expression of brain nitric oxide synthase and soluble guanylyl cyclase in hypothalamus and medulla of two-kidney, one clip hypertensive rats. Hypertension 1995; 26: 171-176. 